\title{
Técnicas de trasplante hepático usadas en el manejo del carcinoma renal de células claras con trombos en la cava inferior que ascienden hasta el diafragma: serie de casos
}

\author{
Liver transplant techniques used in the management of clear renal cell \\ carcinoma with thrombi in the inferior vena cava that ascend to the \\ diaphragm: case series
}

\author{
Luis Manuel Barrera1', Fabio Alejandro Vergara ${ }^{1}$, Mauricio Francisco Duque ${ }^{1}$, \\ Lesly Roxana Suaza², Néstor David Rivillas², Jaime Alberto Ramírez' \\ 1 Unidad de Cirugía Hepatobiliopancreática y Trasplante de Órganos Abdominales, IPS Universitaria, Servicios de Salud-Universidad \\ de Antioquia, Medellín, Colombia \\ 2 Médico, residente de Urología, Departamento de Urología, Universidad de Antioquia, Medellín, Colombia
}

\section{Resumen}

Introducción. El carcinoma de células renales corresponde al $3 \%$ de todos los tumores sólidos y, de ellos, cerca del Io \% tiene compromiso de la vena cava inferior. La nefrectomía con trombectomía es la mejor alternativa con intención curativa. La mortalidad perioperatoria se encuentra entre el 2 y el iI \%.

El objetivo del presente estudio fue presentar una serie de casos de carcinomas renales con trombos de tipo III según la clasificación de Neves-Zincke, en los cuales se usaron con éxito técnicas del trasplante hepático para su extracción.

Materiales y métodos. Se presenta una serie de cinco casos, de pacientes sometidos a nefrectomía radical y que presentaban trombo de la vena cava inferior, atendidos en el periodo comprendido entre enero de 2012 y septiembre de 2018.

Resultados. De 26 pacientes encontrados con cáncer de células renales, se seleccionaron cinco con trombos de tipo Neves III, cuatro de ellos de tipo IIIa y uno de tipo IIIc.

El promedio de edad fue de 63,2 años, cuatro mujeres y un hombre. El promedio de tiempo operatorio fue de 274 minutos y el de pinzamiento de la vena cava inferior fue de 13,6 minutos. El tiempo promedio de estancia en la unidad de cuidados intensivos fue de 2,8 días y el de estancia hospitalaria fue de 9,6 días. Un paciente no

Fecha de recibido: 19/10/2018 - Fecha de aceptación: 8/03/2019

Correspondencia: Luis Manuel Barrera, MD, Calle 7 sur N²3-91, apartamento 1601, Medellín, Colombia, Teléfono: (57) (301) 769-6911 Correo electrónico: luismanuelbarrera@gmail.com

Citar como: Barrera LM, Vergara FA, Duque MF, Suaza LR, Rivillas ND, Ramírez JA. Técnicas de trasplante hepático usadas en el manejo del carcinoma renal de células claras con trombos en la cava inferior que ascienden hasta el diafragma: serie de casos. Rev Colomb Cir. 2019;34:260-8. https://doi.org/10.30944/20117582.442

Este es un artículo de acceso abierto bajo una Licencia Creative Commons - BY-NC-ND https://creativecommons.org/licenses/by-nc-nd/4.0/deed.es 
presentó ninguna complicación, y los cuatro restantes presentaron complicaciones quirúrgicas menores, I y II de la clasificación de Clavien-Dindo.

Conclusión. El uso de maniobras técnicas del trasplante hepático para extraer trombos de la vena cava inferior que no comprometen la aurícula derecha en pacientes con tumores renales, es una alternativa segura con baja morbimortalidad perioperatoria y que puede llegar a garantizar el control de la enfermedad a largo plazo.

Palabras clave: neoplasias renales; vena cava inferior; trombosis; procedimientos quirúrgicos; trasplante de hígado.

\begin{abstract}
Introduction. Renal cell carcinoma corresponds to 3\% of all solid tumors and about I0\% have IVC thrombus. Nephrectomy with thrombectomy is the best choice for a curative treatment. Perioperative mortality may vary between 2 and II\%. The aim of this study is to describe a series of patients with renal tumors and IVC thrombus Neves III in treated succesfully with liver transplant techniques.

Materials and methods. We conducted a descriptive case series of five patients who underwent nephrectomy and thrombectomy between January 2012 and September 2018.

Results. Of 26 nephectomized patients who had any IVC thrombus, five cases had renal tumors and thrombus Neves III. The mean age was 63.2 years and $80 \%$ were women. Eighty percent were Neves IIIa. Mean operative time and IVC clamping were 274 and 13.6 minutes respectively. ICU and hospital stay were 2.8 and 9.6 days. Twenty percent of patients had no complications, the rest had minor complications (Clavien-Dindo I and II).

Conclusion. IVC thrombus extraction with liver transplantion technique for renal tumors without right atrium involvement is a safe alternative for patients with low morbility and mortality. It is also a feasible alternative to ensure disease control in a long term.
\end{abstract}

Key words: kidney neoplasms; vena cava, inferior; thrombosis; surgical procedures; liver transplantation.

\section{Introducción}

El carcinoma renal de células claras corresponde al $3 \%$ de todos los tumores sólidos del adulto ${ }^{1}$, de los cuales cerca del Io \% se acompañan de compromiso de la vena cava inferior ${ }^{2}$. Cuando esto sucede, la supervivencia promedio es de cinco meses y la probabilidad de estar vivo al año del diagnóstico es solo del $29 \%{ }^{3}$. Lo anterior obligó a buscar alternativas para su manejo, pues no se contaba con un tratamiento eficaz que mejorara el resultado.

El avance de las técnicas quirúrgicas después de los años 70, dio la oportunidad a la resección oncológica con trombectomía de mostrar una superioridad por encima de otros tratamientos, como la quimioterapia, la radioterapia o la inmunoterapia, no solo para controlar las consecuencias de la enfermedad (tromboembolia pulmonar, hipertensión venosa esplácnica y edemas masivos de miembros inferiores), sino tam- bién, para mejorar la supervivencia a largo plazo. El tratamiento quirúrgico tiene una mortalidad perioperatoria entre el 2 y el II $\% 4$. El tratamiento por grupos con amplia experiencia y abordajes multidisciplinarios ha logrado una supervivencia hasta de $64 \%$ a cinco años, sin importar la extensión del trombo tumoral 5 .

La clasificación de este tipo de trombos tumorales más usada, es la descrita por Neves y Zincke $^{6}$. El trombo de tipo I compromete la vena renal; el de tipo II, la vena cava inferior infrahepática; el de tipo III, la vena cava inferior retrohepática (figura I), y el de tipo IV se extiende hasta la aurícula derecha. La evidencia es clara con respecto al abordaje quirúrgico de trombos de tipo I, pues en ellos el control vascular y la trombectomía no requieren una importante movilización hepática (figura 2). Los trombos de tipo IV requieren, inevitablemente, paro cardiaco y circulación extracorpórea ${ }^{4}$. 


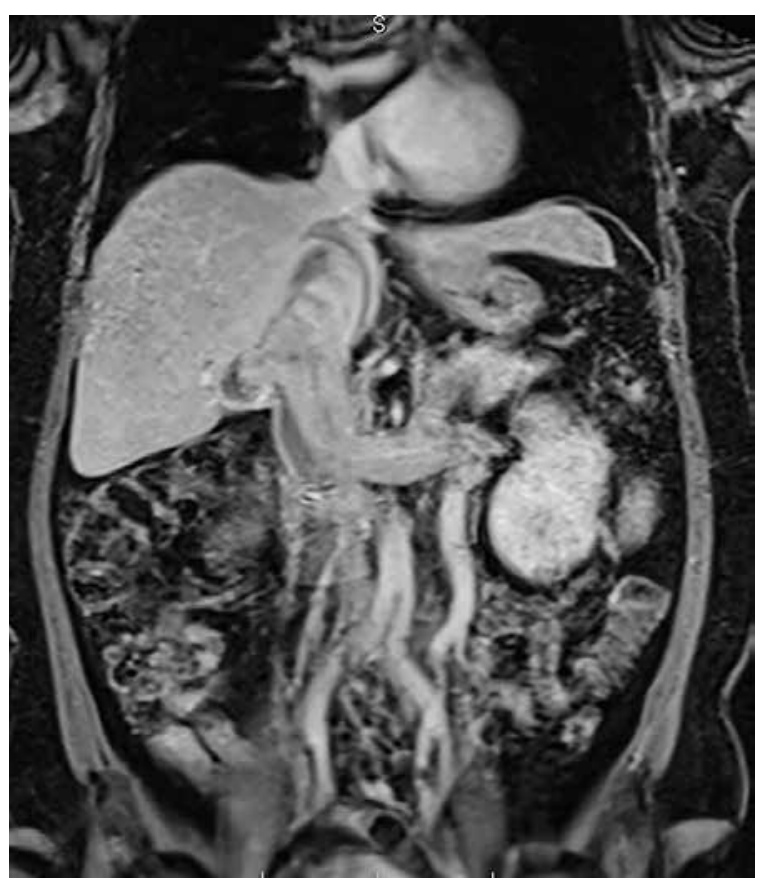

Figura 1. Corte coronal de resonancia magnética contrastada con gadolinio: tumor renal izquierdo con trombo de tipo Neves III, oclusión total de la vena renal izquierda y de la vena cava inferior retrohepática, con hipertensión venosa, múltiples colaterales y gran dilatación de la vena gonadal izquierda

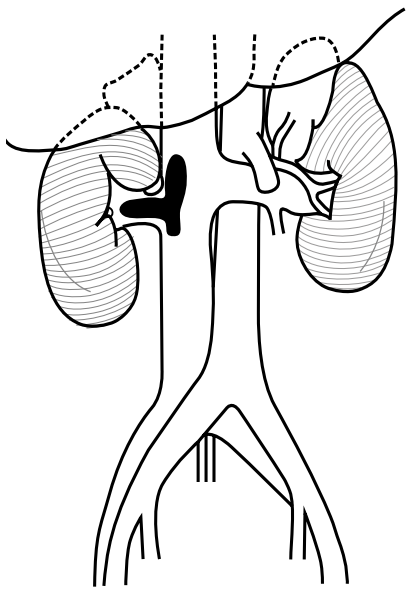

Neves I

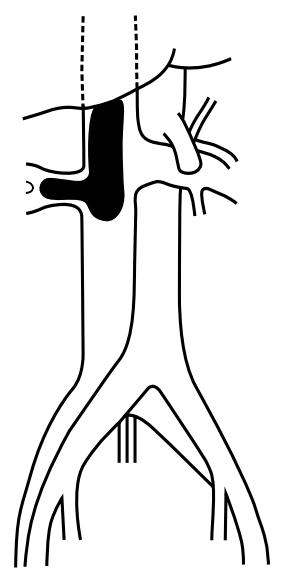

Neves II

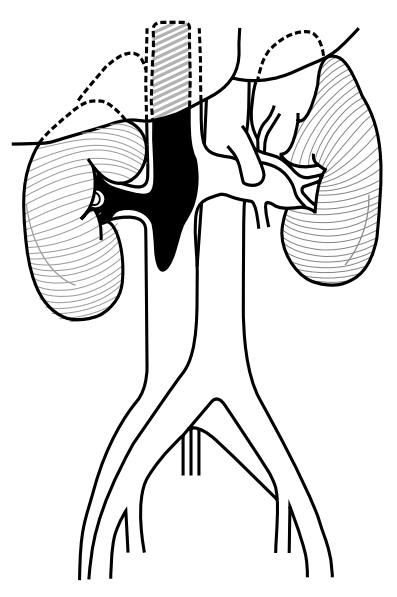

Neves III

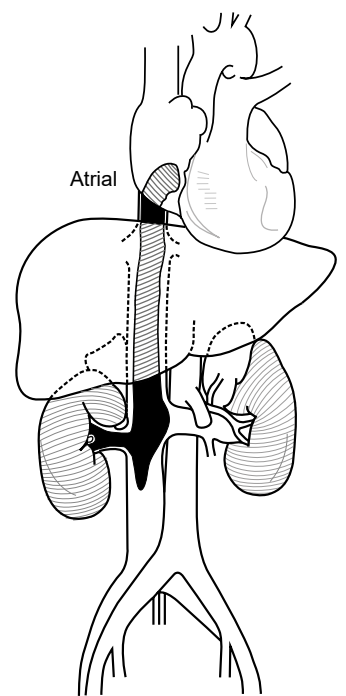

Neves IV

Figura 2. Clasificación de Neves-Zincke: Neves I, compromete la vena renal; Neves II, el trombo se extiende hasta la vena cava inferior infrahepática; Neves III, el trombo se extiende por la vena cava inferior retrohepática; Neves IV, el trombo llega hasta la aurícula.

Reproducido con permiso de: Neves RJ, Zincke H. Surgical treatment of renal cancer with vena cava extension. Br J Urol. 1987;59:390-5. 


\section{Materiales y métodos}

En el periodo comprendido entre enero de 2012 y septiembre de 20I8, se identificaron los pacientes sometidos a nefrectomía radical y que presentaban trombo de la vena renal y de la vena cava inferior, atendidos por los grupos de Urología y de Cirugía de Trasplantes de la Universidad de Antioquia.

Se identificaron cinco pacientes que tenían trombos que se extendían hasta las venas suprahepáticas. Se evaluaron sus características sociodemográficas y clínicas, las variables intraoperatorias (tiempo operatorio, tiempo de pinza hepática, renal contralateral y de la vena cava, y sangrado) y los resultados posoperatorios (estancia en hospitalaria y en la unidad de cuidado intensivo, mortalidad a 30 días, y complicaciones según Clavien-Dindo).

\section{Técnica quirúrgica}

El abordaje descrito solo se utilizó en los pacientes con trombos de tipo III de Neves-Zincke y en ninguno de ellos se usaron filtros de vena cava por vía transyugular antes de la cirugía.

El paciente se coloca en decúbito supino y se procede a hacer una incisión en L o de Mackuuchi si el tumor es del riñón derecho y, una en Mercedes Benz o incisión de Calné, si es del izquierdo.

Una vez explorada la cavidad, se fijan los colgajos miocutáneos de la incisión y se coloca el retractor subcostal de tipo Thompson. Se procede con la maniobra de Cattell-Braasch y luego con la de Kocher, hasta lograr la exposición completa del tumor, de la vena cava infrarrenal y de las venas renales bilaterales. Este tipo de trombos oclusivos generan un grado importante de circulación colateral y de hipertensión venosa, que aumentan el riesgo de sangrado hasta que no se resuelva el fenómeno oclusivo, por lo que el uso del salvador de células queda a discreción del cirujano y del anestesiólogo del equipo.

La liberación circunferencial de la vena cava inferior infrarrenal (incluye ligadura de la vena gonadal derecha y los ramos lumbares) es de radical importancia, no solo para el pinzamiento, sino para un posible cateterismo en caso de necesitarse un cortocircuito venovenoso ${ }^{\text {II }}$.

Antes de proceder a cualquier disección de los vasos renales, se procede al control proximal de la vena cava inferior retrohepática por encima del trombo. Para tal efecto, se libera el hígado del ligamento falciforme hasta obtener la completa visualización de las venas suprahepáticas a su entrada en la vena cava; se ligan las venas frénicas y se libera la vena cava del diafragma de forma circunferencial por encima de las venas suprahepáticas. Por otro lado, para evitar cualquier posible accidente vascular proximal o hemorragia del hígado, se repara el ligamento hepatoduodenal para un potencial pinzamiento del pedículo hepático (maniobra de Pringle).

La vena cava inferior retrohepática se diseca mediante la maniobra de movilización hepática completa (piggy-back), la cual se lleva a cabo mediante la liberación de los ligamentos triangulares derechos, exponiendo el área desnuda. Una vez identificada la cava, se ligan los ramos que drenan el hígado hacia ella; entre estos, se encontró el ramo venoso postero-inferior o vena de Mackuuchi, la cual llegó a diámetros de hasta $12 \mathrm{~mm}$ en nuestra serie. En este punto, se puede lograr la disección circunferencial de la cava por encima de la trombosis con mayor facilidad. Sin embargo, una vez logrados los reparos proximal y distal, no hubo necesidad de completar la disección en $360^{\circ}$, de hecho, con la exposición de la cara anterior o de $180^{\circ}$ de la circunferencia de vena cava inferior donde se encontraba la trombosis en toda su longitud, fue suficiente para lograr la potencial venotomía.

Después se procede a la disección y el reparo de las venas y arterias renales. En el caso de los tumores del riñón derecho, el reparo de la vena renal izquierda es más que suficiente, y no hay necesidad de reparar la arteria renal izquierda para el pinzamiento, dado que su drenaje venoso se logra con los flujos de salida por las venas gonadal izquierda, suprarrenal izquierda y lumbar. En los tumores renales izquierdos, se requirió no solo la disección de la vena, sino también, la de 
la arteria renal derecha para los pinzamientos respectivos.

Antes de proceder al pinzamiento venoso por encima del trombo en la vena cava inferior, se hizo una evaluación imaginológica preoperatoria, y se utilizó la clasificación descrita por Ciancio, et al. ${ }^{\text {I2 }}$ para definir el orden y la forma de pinzamiento (figura 3):

Trombos de tipo Neves IIIa. Se localizan por debajo del ostium de las suprahepáticas y permiten el pinzamiento de la vena cava inferior

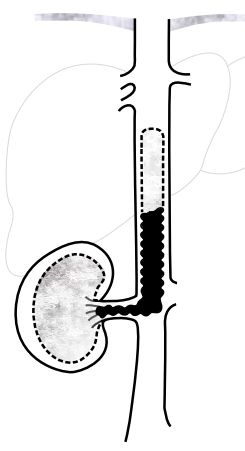

Intrahepático

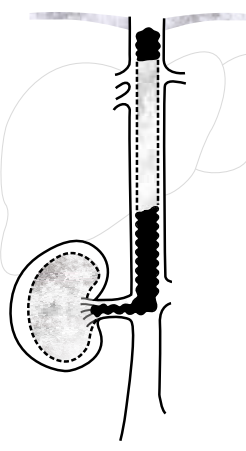

Suprahepático

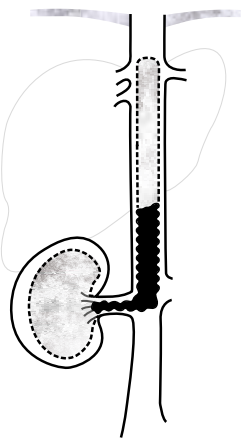

Hepático

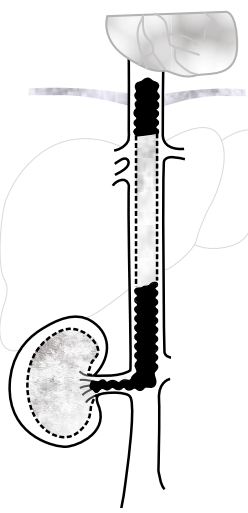

Supradiafragmático
Figura 3. Subclasificación de trombos Neves III: IIla, intrahepático, sin llegar a las venas suprahepaticas,; IIIb, hepático: se extiende hasta el ostium de las venas suprahepáticas; Illc, suprahepático: el trombo supera el ostium de las venas suprahepáticas; IIld, supradiafragmática: el trombo atraviesa el diafragma, pero sin comprometer la aurícula derecha.

Reproducido con permiso de: Ciancio G, Vaidya A, Savoie M, Soloway $M$. Management of renal cell carcinoma with level III thrombus in the inferior vena cava. J Urol. 2002;168(4Pt1):1374-7. retrohepática por debajo, sin necesidad de la maniobra de Pringle o de pinzamientos de las venas suprahepáticas individualmente (figura 4).

Trombos de tipo Neves IIIb. Estos llegan hasta el ostium de las suprahepáticas, pero están por debajo del diafragma. Para el control adecuado, se usa la maniobra de Pringle y el pinzamiento individual de las venas suprahepáticas antes de su llegada, además de pinzar la vena cava inferior por encima del trombo.

Trombos de tipo Neves IIIc. Estos se extienden por encima del ostium de las suprahepáticas, pero por debajo del diafragma. Para lograr pinzar la vena cava inferior por encima del trombo, se debe abrir de forma longitudinal y anterior el diafragma, y exponer la vena cava inferior intrapericárdica. Lo anterior incluye pinzamientos del hilio hepático y de venas suprahepáticas.

Trombos de tipo Neves IIId. Estos se extienden por encima del ostium de las suprahepáticas y del diafragma, y llegan hasta la aurícula derecha sin

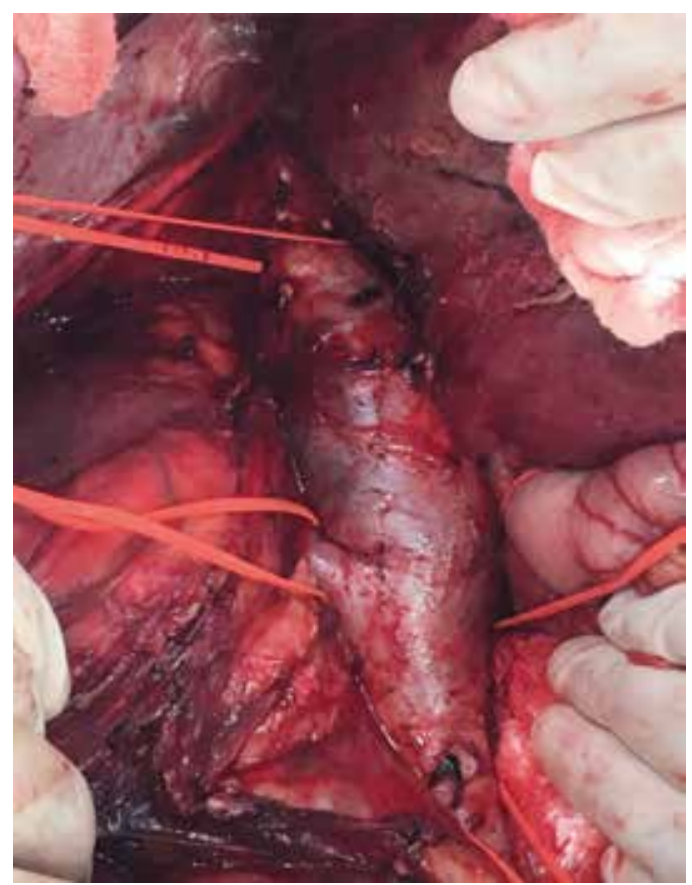

Figura 4. Disección completa de la vena cava inferior retrohepática; reparos proximal y distal al trombo, además de las venas renales. 
ingresar en ella. Se deben usar las mismas maniobras que en los IIIc. Sin embargo, en este caso, el pinzamiento se puede hacer sobre la aurícula derecha y, después de pinzar las venas suprahepáticas, se puede proceder con una maniobra de ordeño, desplazando el trombo hacia el área de la venotomía.

Los pinzamientos se hacen en dirección distal a proximal, en el siguiente orden: vena cava inferior infrarrenal, renales contralaterales (arterial y luego venoso), pedículo vascular hepático, suprahepáticas (si es necesario), y vena cava inferior por encima del trombo. Posteriormente, se practica una venotomía longitudinal de aproximadamente de 5 a $10 \mathrm{~cm}$, según la extensión del trombo. Una vez completada la trombectomía, se lava la vena cava inferior con una solución con 5.000 unidades de heparina no fraccionada, se sutura la cava en dos planos continuos con polipropileno 5.0 y se sueltan las pinzas en el mismo orden en que se colocaron (figura 5). Una vez completada la trombectomía, se continúa con la nefrectomía radical de la forma usual (figura

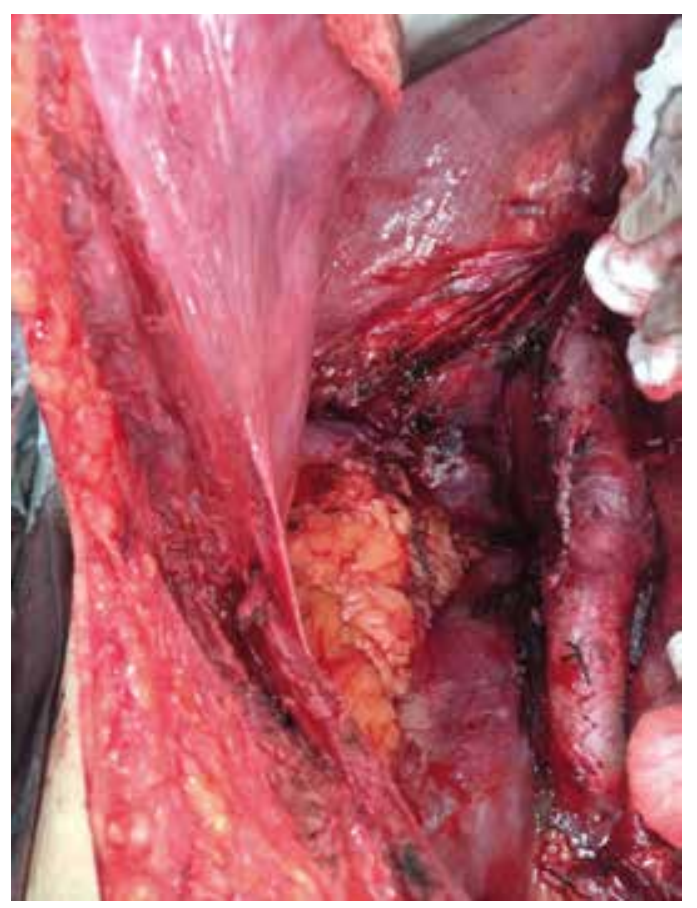

Figura 5. Sutura en dos planos de la vena cava inferior retrohepática, con polipropileno 4.0
6). Se seleccionaron cinco pacientes con trombos de tipo Neves III, cuatro de ellos de tipo IIIa y uno de tipo IIIc.

\section{Resultados}

Se identificaron 26 pacientes con trombos renales con extensión a la vena cava inferior, de los cuales se seleccionaron cinco con trombos de tipo Neves-Zincke III, cuatro de ellos de tipo IIIa $\mathrm{y}$ uno de tipo IIIc.

El promedio de edad fue de 63,2 años, cuatro mujeres y un hombre. Tres tumores se localizaron en el riñón derecho y dos en el izquierdo; cuatro eran Neves IIIa y solo uno Neves IIIc. De los 26 pacientes identificados inicialmente con trombo renal, cinco tenían trombos de tipo Neves II y tres de tipo Neves IV; en ninguno de ellos se usaron técnicas de trasplante hepático. De los pacientes Neves III de esta serie, el promedio de la hemoglobina preoperatoria fue de II, $9 \mathrm{mg} / \mathrm{dl}$ y ningún paciente presentó disfunción renal (tablas I y 2).

La media del tiempo operatorio fue de $274 \mathrm{mi}$ nutos y, el sangrado promedio, de $2.680 \mathrm{ml}$. Solo un paciente no requirió transfusión con hemoderivados y en uno solo de ellos se usó el salvador de células. El tiempo promedio de pinzamiento de la vena cava inferior fue de 13,6 minutos, y solo

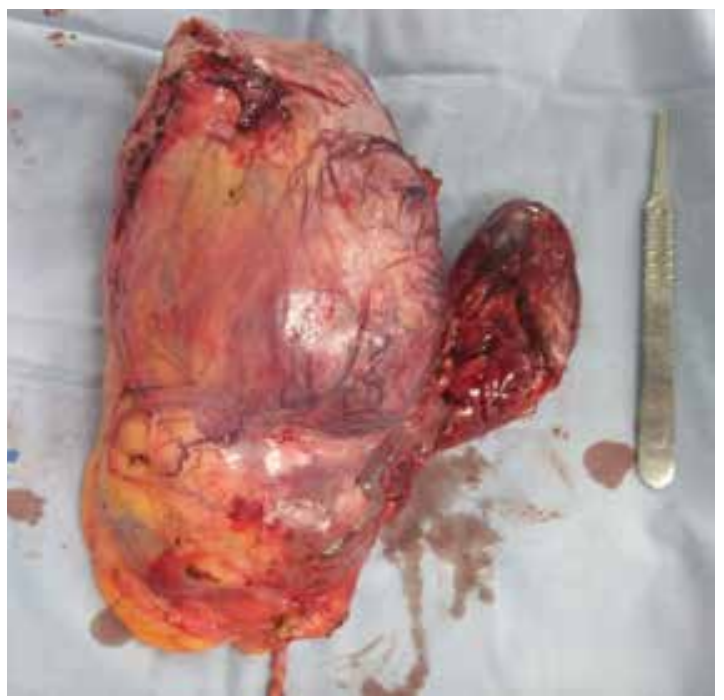

Figura 6. Riñón derecho con trombo de vena cava inferior de tipo Neves IIla, en bloque 
Tabla 1. Características de los pacientes con carcinoma renal de células claras y con trombos en la vena cava inferior de tipo Neves III.

\begin{tabular}{|c|c|c|c|c|c|c|c|c|c|c|c|c|c|c|c|c|c|}
\hline Sexo & $\begin{array}{l}\text { Edad } \\
\text { (años) }\end{array}$ & ASA & Lado $\mathrm{N}$ & Neves & $\begin{array}{l}\text { Tamaño del } \\
\text { tumor }(\mathrm{cm})\end{array}$ & Incisión & $\begin{array}{c}\text { Tiempo } \\
\text { quirúrgico } \\
\text { (minutos) }\end{array}$ & $\begin{array}{l}\text { Hemoglobina } \\
\text { prequirúrgica }\end{array}$ & $\begin{array}{c}\text { Sangrado } \\
(\mathrm{ml})\end{array}$ & $\begin{array}{l}\text { Hemoderivados } \\
\text { (unidades) }\end{array}$ & Pringle & $\begin{array}{l}\text { Pinzamiento } \\
\text { de arteria } \\
\text { renal }\end{array}$ & $\begin{array}{c}\text { Pinzamiento } \\
\text { de } \mathrm{VCl}\end{array}$ & $\begin{array}{c}\text { Estancia } \\
\text { hospitalaria } \\
\text { (días) }\end{array}$ & $\begin{array}{l}\text { Estancia } \\
\text { UCI (días) }\end{array}$ & $\begin{array}{l}\text { Dindo- } \\
\text { Clavien }\end{array}$ & Tipo \\
\hline Femenino & 63 & III I & Izquierdo & IIla & 14 & Mercedes & 360 & 10,7 & 2.000 & $4 \mathrm{GR}+4 \mathrm{PFC}$ & No & No & 15 & 17 & 4 & II & $\begin{array}{c}\text { TEP lóbulo inferior } \\
\text { derecho }\end{array}$ \\
\hline Masculino & 62 & "I & Derecho & IIla & 20 & $\begin{array}{l}\text { Incisión } \\
\text { en L }\end{array}$ & 240 & 13 & 4.000 & $\begin{array}{l}7 \mathrm{GR}+5 \mathrm{PFC} \\
+1 \text { plaquetas }\end{array}$ & No & No & 20 & 12 & 2 & $\|$ & Íleo \\
\hline Femenino & 66 & ॥ & Derecho & IIIa & 15 & $\begin{array}{l}\text { Incisión } \\
\text { en L }\end{array}$ & 200 & 13 & 2.800 & $3 \mathrm{GR}+3 \mathrm{PFC}$ & No & No & 8 & 4 & 3 & No & \\
\hline Femenino & 66 & II & Derecho & IIla & 14 & $\begin{array}{l}\text { Incisión } \\
\text { en L }\end{array}$ & 240 & 13 & 600 & No & No & No & 8 & 8 & 3 & 1 & Íleo \\
\hline Femenino & 59 & II & Izquierdo & IIIc & 15 & Mercedes & 330 & 10 & 4.000 & $\begin{array}{c}6 \mathrm{GR}+3 \mathrm{PFC}+ \\
1 \text { aféresis }\end{array}$ & 16 & 16 & 17 & 7 & 2 & II & TVP proximal \\
\hline
\end{tabular}

ASA: Clasificación American Society of Anesthesiologists; GR: glóbulos rojos; PFC: plasma fresco congelado; VCI: vena cava inferior; UCI: unidad de cuidados intensivos; TEP: tromboembolismo pulmonar; TVP: trombosis venosa profunda

Tabla 2. Características de los carcinomas renales de células claras

\begin{tabular}{|c|c|c|c|c|c|c|c|c|c|}
\hline Histología & Fuhrman & Estadio T & Metastásico & $\begin{array}{c}\text { Sitio } \\
\text { metástasis }\end{array}$ & Motzer & $\begin{array}{c}\text { Invasión } \\
\text { linfovascular }\end{array}$ & Sarcomatoide & Necrosis & Márgenes \\
\hline Celulas claras & 4 & pT3cN1M1 & Sí & Pulmón & Intermedio & Sí & Sí & Sí & Negativos \\
\hline Celulas claras & 4 & pT3bNXMO & No & & Intermedio & Sí & No & $40 \%$ & Negativos \\
\hline Celulas claras & 2 & pT3aN0M1 & Sí & Pulmón & Sin dato & No & No & No & Negativos \\
\hline Celulas claras & 2 & pT3aNOMO & No & & Bajo & No & No & No & Negativos \\
\hline Celulas claras & 4 & $\mathrm{pT} 3 \mathrm{bN} 1 \mathrm{M} 0$ & No & & Intermedio & Sí & Sí & $20 \%$ & Negativos \\
\hline
\end{tabular}

un paciente requirió pinzamiento renal y hepático (I6 minutos en ambos). El tiempo promedio de estancia en la unidad de cuidados intensivos fue de 2,8 días y el de estancia hospitalaria fue 9,6 días.

Un paciente no presentó ninguna complicación, en dos hubo complicaciones de tipo Clavien-Dindo I (íleo) y en los dos restantes, de tipo Clavien-Dindo II. Uno de ellos presentó trombosis venosa profunda proximal, por debajo de la pinza infrarrenal, la cual se manejó con anticoagulación y medias con gradiente de compresión. El otro paciente presentó una embolia aguda en el postoperatorio inmediato después de la extracción total del trombo; este trombo no tuvo repercusión hemodinámica ni en la oxigenación, motivo por el cual se manejó con anticoagulación plena; sin embargo, presentó infección del sitio operatorio superficial, que se manejó con curaciones hospitalarias y domiciliarias de forma exitosa. Por último, de los ocho casos con trombos de tipo Neves II o IV, cuatro presentaron complicaciones ClavienDindo V, es decir, muerte.

\section{Discusión}

El venotropismo que tienen los carcinomas de células renales es su característica distintiva. Cerca del $35 \%$ de ellos tiene compromiso de la vena renal y, el io \%, de la vena cava inferior ${ }^{2,3}$. A pesar de su gran frecuencia, en la literatura científica nacional solo hay reportada una serie de nueve casos, de los cuales tres presentaban trombos de tipo Neves III ${ }^{13}$. Este es el primer estudio que se detiene a analizar una técnica que ofrece una menor morbimortalidad que la intervención con circulación extracorpórea.

Definitivamente, la maniobra de movilización hepática completa (piggy-back) cambió la historia del implante de los injertos hepáticos ${ }^{14}$. Dicha maniobra permite la preservación completa de la vena cava inferior, evita pinzamientos totales 
prolongados y mantiene una mayor estabilidad hemodinámica intraoperatoria, además de disminuir la necesidad de circulación extracorpórea (derivación o bypass veno-venoso) ${ }^{\text {II }}$. Ciancio, et al., describieron la homologación de esta técnica quirúrgica para tratar los trombos de la vena cava inferior, lo cual aumentó de forma notable la seguridad de este tipo de cirugías haciendo innecesaria la circulación extracorpórea, la cual conlleva mayor morbimortalidad ${ }^{\text {io }}$. En la presente serie se usó dicha técnica en todos los casos con trombos de tipo Neves III, y se lograron resultados similares a los descritos en la literatura.

El tiempo operatorio promedio de la trombectomia más nefrectomía radical descrito en la literatura se encuentra entre 256 y 342 minutos 12,15. Sin embargo, el menor tiempo promedio corresponde a la intervención de los trombos de tipo Neves I y II ${ }^{15}$. En la presente serie, el tiempo operatorio promedio se encuentra por debajo de lo reportado en el mundo, inclusive, teniendo en cuenta el tiempo invertido en el trombo de tipo Neves IIIc, el cual no fue mayor que en los demás casos, y la omisión de la circulación extracorpórea (derivación o bypass veno-venoso).

La preservación de la vena cava inferior permite establecer, antes de cualquier trombectomía, si el paciente puede tolerar o no un pinzamiento total de la vena cava inferior. La oclusión total de la vena cava inferior genera en el organismo una caída del $50 \%$ del índice cardiaco. Sin embargo, esto es bien tolerado debido a un aumento de la resistencia vascular sistémica y a un leve aumento de la frecuencia cardiaca, así, en teoría, un organismo puede tolerar hasta 60 minutos de pinzamiento total de la vena cava inferior ${ }^{\mathrm{II}}$.

Lamentablemente, los tiempos prolongados de pinzamiento de la cava pueden generar grandes edemas esplácnicos o de los miembros inferiores y, además, una caída de $50 \%$ de la presión de perfusión renal, generada por aumento de la presión de flujo de salida de la vena renal, el cual disminuye la presión arterial media del riñón ${ }^{16}$. El tiempo promedio de pinzamiento de la cava en los trombos de tipo Neves III es de I7,2 minutos y el pinzamientos hepático o renal no impactaron el tiempo de oclusión total de vena cava inferior ${ }^{15}$.

En la presente serie, este tiempo estuvo por debajo de lo descrito $y$, al igual que en el trabajo de Galluccci, et al., los pinzamientos renales y hepáticos no aumentaron notoriamente el tiempo total de pinzamiento de la cava. Por otro lado, los pinzamientos completos no disminuyen el volumen de sangrado intraoperatorio; se han descrito sangrados de un volumen promedio entre 450 y $500 \mathrm{ml}^{12,15}$. Sin embargo, a mayor proximidad del trombo a la aurícula, mayor es el sangrado intraoperatorio (hasta $3.500 \mathrm{ml}$ ). Lo anterior se correlaciona de forma similar en nuestra serie, se encontró mayor sangrado en el trombo Neves IIIc; sin embargo, disminuyó ostensiblemente el sangrado en los otros casos en la medida en que se realizaban más procedimientos.

La complicación más temida de esta cirugía es la tromboembolia pulmonar masiva ${ }^{17,18}$. Múltiples estrategias preventivas, como el filtro preoperatorio en la vena cava inferior, se han explorado para evitar la embolia durante la movilización hepática ${ }^{19}$. Sin embargo, las guías de manejo multidisciplinario no recomiendan su uso rutinario ${ }^{20}$. Vale la pena aclarar que, a pesar de la técnica de trombectomía más nefrectomía, cerca del $37 \%$ de los pacientes quedan con trombo residual en la vena cava inferior. Justamente el trombo residual es el principal factor de riesgo para el desarrollo de tromboembolismo pulmonar después de la nefrectomía, $27,8 \%$ en pacientes con trombo residual en la vena cava inferior frente a 3,3\% con resección total del trombo. Sin embargo, estos eventos posquirúrgicos no tuvieron ningún impacto en la supervivencia de los pacientes después de dos años de seguimiento ${ }^{21}$. En la presente serie, dos pacientes sufrieron tromboembolia, sin impacto hemodinámico. En uno, se logró la resección completa del trombo, pero desarrolló una trombosis venosa profunda proximal poco después de la cirugía, por estasis venosa y el estado de hipercoagulabilidad secundario al cáncer, lo cual es poco esperado según lo descrito anteriormente. En el otro caso, también se logró la resección completa, pero un pequeño 
fragmento del trombo, con aspecto sarcomatoso y desmechado, logró desprenderse antes del pinzamiento. Ambos pacientes recibieron anticoagulación con heparinas de bajo peso molecular (HPBM) por tiempo indefinido.

\section{Conflicto de intereses: no existió ninguno.}

Fuente de financiación: este trabajo fue autofinanciado.

\section{Referencias}

I. Ljungberg B, Bensalah K, Canfield S, Dabestani S, Hofmann F, Hora M, et al. EAU guidelines on renal cell carcinoma: 2014 update. Eur Urol. 2015;67:913-24.

2. Marshall FF. Surgery of renal cell carcinoma with inferior vena caval involvement. Semin Urol. 1989;7:186-90.

3. Reese AC, Whitson JM, Meng MV. Natural history of untreated renal cell carcinoma with venous tumor thrombus. Urol Oncol. 2013;31:1305-9.

4. Wotkowicz C, Wszolek MF, Libertino JA. Resection of renal tumors invading the vena cava. Urol Clin North Am. 2008;35:657-7I.

5. Ciancio G, Manoharan M, Katkoori D, De Los Santos $\mathrm{R}$, Soloway MS. Long-term survival in patients undergoing radical nephrectomy and inferior vena cava thrombectomy: Single-center experience. Eur Urol. 2010;57:667-72.

6. Neves RJ, Zincke H. Surgical treatment of renal cancer with vena cava extension. Br J Urol. 1987;59:390-5.

7. Babu SC, Mianoni T, Shah PM, Goyal A, Choudhury M, Eshghi M, et al. Malignant renal tumor with extension to the inferior vena cava. Am J Surg. 1998;176:137-9.

8. Nesbitt JC, Soltero ER, Dinney CP, Walsh GL, Schrump DS, Swanson DA, et al. Surgical management of renal cell carcinoma with inferior vena cava tumor thrombus. Ann Thorac Surg. 1997;63:1592-600.

9. Wotkowicz C, Libertino JA, Sorcini A, Mourtzinos A. Management of renal cell carcinoma with vena cava and atrial thrombus: Minimal access vs. median sternotomy with circulatory arrest. BJU Int. 2006;98:289-97.

Io. Ciancio G, González J, Shirodkar SP, Angulo JC, Soloway MS. Liver transplantation techniques for the surgical management of renal cell carcinoma with tu- mor thrombus in the inferior vena cava: Step-by-step description. Eur Urol. 201I;59:40I-6.

II. Reddy K, Mallett S, Peachey T. Venovenous bypass in orthotopic liver transplantation: Time for a rethink? Liver Transplant. 2005;II:74I-9.

I2. Ciancio G, Vaidya A, Savoie M, Soloway M. Management of renal cell carcinoma with level III thrombus in the inferior vena cava. J Urol. 2002;168:I374-7.

13. López D, Cajigas J, Quiroga W, Citarela D. Manejo quirúgico de los tumores renales con trombo en cava. Rev Urol Colomb. 2008;18:I49-55.

I4. Tzakis A, Todo S, Starzl TE. Orthotopic liver transplantation with preservation of the inferior vena cava. Ann Surg. 1989;210:649-52.

15. Gallucci M, Borzomati D, Flammia G, Alcini A, Albino $\mathrm{G}$, Caricato M, et al. Liver harvesting surgical technique for the treatment of retro-hepatic caval thrombosis concomitant to renal cell carcinoma: Perioperative and long-term results in 15 patients without mortality. Eur Urol. 2004;45:194-202.

I6. Peachey T, Eason J, Potter D, Ginsburg R. Observations on abdominal venous pressures during orthotopic liver transplantation in man. Transplant Proc. 1989;21:3526-7.

I7. Galvez JA, Clebone A, Garwood S, Popescu WM. Fatal intraoperative cardiac thrombosis in a patient with renal cell carcinoma. Anesthesiology. 20II;II4:I212.

I8. Shuch B, Larochelle JC, Onyia T, Vallera C, Margulis D, Pantuck AJ, et al. Intraoperative thrombus embolization during nephrectomy and tumor thrombectomy: Critical analysis of the University of California-Los Angeles experience. J Urol. 2009;181:492-9.

19. Zhang J, Zhu Y, Liu Y, Zhang L, Sun L, Guo J, et al. Temporary filters and liver mobilization technique improve the safety and prognosis of radical nephrectomy and inferior vena cava thrombectomy in renal cell carcinoma with subdiaphragmatic thrombosis. Urol Int. 20I3;9I:279-84.

20. Lawindy SM, Kurian T, Kim T, Mangar D, Armstrong $\mathrm{PA}$, Alsina AE, et al. Important surgical considerations in the management of renal cell carcinoma (RCC) with inferior vena cava (IVC) tumour thrombus. BJU Int. 2OI2;IIO:926-39.

2I. Ihaddadene R, Yokom DW, Le Gal G, Moretto P, Canil $\mathrm{CM}$, Delluc A, et al. The risk of venous thromboembolism in renal cell carcinoma patients with residual tumor thrombus. J Thromb Haemost. 20I4;I2:855-9. 